\title{
Erratum to: Trends in gastric cancer incidence: a period and birth cohort analysis in a well-defined French population
}

\author{
Nicolas Chapelle $^{1} \cdot$ Sylvain Manfredi $^{1} \cdot$ Come Lepage $^{1} \cdot$ Jean Faivre $^{1} \cdot$ \\ Anne-Marie Bouvier ${ }^{1}$. Valérie Jooste ${ }^{1}$
}

Published online: 7 October 2015

(C) The International Gastric Cancer Association and The Japanese Gastric Cancer Association 2015

\section{Erratum to: Gastric Cancer \\ DOI 10.1007/s10120-015-0509-9}

In the original publication of the article, the author names were swapped in the author group. The correct full list of author names is presented above.

The online version of the original article can be found under doi:10.1007/s10120-015-0509-9.

Valérie Jooste

valerie.jooste@u-bourgogne.fr

1 Digestive Cancer Registry of Burgundy, University Hospital Dijon, INSERM U866, University of Burgundy, 7, bd Jeanne d'Arc, BP 87900, 21079 Dijon Cedex, France 